\title{
Endovascular Repair of Late Onset Anastomosis Site Pseudoaneurysms Complicating Renal Transplantation
}

Narayan Karunanithy FRCR ${ }^{1}$, Raphael Uwechue MRCS ${ }^{2}$, Francis Calder FRCS ${ }^{3}$, NizamMamode FRCS ${ }^{3}$, LetoMailli MD ${ }^{1}$, PankajChandak MRCS $^{3}$, Mohamed Morsy MRCS ${ }^{4}$, Jiri Fronek FRCS ${ }^{5}$, David Makanjuola FRCP6, Derek Roebuck FRCR ${ }^{7}$ and Nicos Kessaris ${ }^{3 *}$

${ }^{1}$ Department of Interventional Radiology, Guy's \& St Thomas' NHS Foundation Trust, London, UK

${ }^{2}$ Department of General Surgery, Diana Princess of Wales Hospital, Grimsby, UK

${ }^{3}$ Department of Nephrology and Renal Transplantation, Guy's \& St Thomas' NHS Foundation Trust, London, UK

${ }^{4}$ Department of Renal and Transplantation Surgery, St George's Healthcare NHS Trust, London, UK

${ }^{5}$ Transplant Surgery Department, Institute for Clinical and Experimental Medicine, 2nd Medical Faculty, Charles University, Prague, Czech Republic

${ }^{6}$ South West Thames Renal and Transplantation Unit, Epsom and St Helier University Hospitals NHS Trust, Surrey, UK

${ }^{7}$ Department of Radiology, Great Ormond Street Hospital for Children NHS Foundation Trust, London, UK

\begin{abstract}
Introduction: Extra-renal anastomosis site pseudoaneurysms are a rare complication that can occur following renal transplantation. Expansion and rupture can lead to life threatening haemorrhage. Definitive treatment options include surgical and endovascular repair. Endovascular repair has shown early promise in management and benefits from being minimally invasive.
\end{abstract}

We report five patients treated with endovascular repair and discuss the factors that need to be considered to tailor individual endovascular treatment strategies.

Methods: Retrospective review of late onset cases of extra-renal pseudoaneurysms managed with endovascular repair at our institutions. Case histories, mode of presentation, imaging, endovascular technique and follow up were analysed. The location, size and configuration of the pseudoaneurysm and the likely underlying aetiology are studied.

Results: Between 2008 and 2013, five patients with six extra-renal pseudoaneurysms were identified. Three of these patients were on warfarin at the time of presentation. Technical success was $100 \%$ (6/6) following endovascular repair, with no significant procedure related complications. 5/6 (83\%) required one procedure and $1 / 6(17 \%)$ required three procedures. No recurrence demonstrated on clinical and imaging follow up.

Conclusions: Endovascular repair is safe and effective in treatment of anastomosis site pseudoaneurysms and results in durable mid-term outcome.

Keywords: Pseudoaneurysm; Endovascular; Anastomosis; Extrarenal; Renal transplant

\section{Introduction}

Transplant anastomosis site pseudoaneurysm is a recognised but rare complication with a reported incidence of $<1 \%$ [1]. Whilst early presentation ( $<30$ days) after transplantation may be related to technical reasons, the aetiology of late onset pseudoaneurysms it not known. These pseudoaneurysms may remain asymptomatic, present with local features such as pain, swelling, compression of adjacent structures or systemic features like anaemia and fever [2-4]. Rupture of the aneurysm can lead to life threatening haemorrhage. Treatment options include open repair [5,6], endovascular repair and percutaneous thrombin injection [7]. We report a series of six cases (1 bilateral, 4 unilateral) presenting with this rare complication that were all successfully treated by endovascular repair. We aim to raise awareness among clinicians of this rare condition including its mode of presentation, aetiology, methods for detection and current therapeutic options.

\section{Case Series}

The study was a retrospective multicentre analysis of all patients who had presented with transplant anastomosis site pseudoaneurysms between 2008 and 2013.Cases that met the following criteria were included: (a) late onset ( $>30$ days after transplantation) anastomosis site pseudoaneurysms, (b) imaging (Duplex or CTA) to confirm findings and (c) underwent endovascular repair. The medical and imaging records were reviewed for the cases that met the inclusion criteria. Data collected included patient demographics, relevant past medical history, pre-operative imaging findings, procedural details and clinical and imaging follow up.

Six cases of anastomosis site pseudoaneurysms in five patients (one bilateral) met the inclusion criteria and were included in this study. The demographic details, relevant past medical history and presentations are shown in Table 1. The pseudoaneurysm in all the cases presented some time after transplantation (range 1 year 8 months -17 years). The mode of presentation was either an incidental finding (3/6), pain $(2 / 6)$ and rupture (1/6). Incidentally none of the cases manifest evidence of sepsis at the time of presentation. In all but one instance the allograft had been explanted some time previously. The site of the anastomosis was the external iliac artery in 5 instances and in the paediatric case the distal abdominal aorta. This is in keeping with our current practise

*Corresponding author: NicosKessaris, Consultant Transplant Surgeon Department of Nephrology and Renal Transplantation,6th Floor, Borough Wing, Guy's Hospital, Great Maze Pond, London SE1 9RT, UK, Tel: +44 (0) 2071887188 Ext: 53493; Fax: +44 (0) 2071885646; E-mail: Nicos.Kessaris@gstt.nhs.uk

Received June 26, 2014; Accepted September 18, 2014; Published September 20, 2014

Citation: Narayan Karunanithy FRCR, Raphael Uwechue MRCS, Francis Calder FRCS, NizamMamode FRCS, LetoMailli MD, et al. (2014) Endovascula Repair of Late Onset Anastomosis Site Pseudoaneurysms Complicating Renal Transplantation. J Vasc Med Surg 2: 156. doi: 10.4172/2329-6925.1000156

Copyright: (c) 2014 Narayan Karunanithy FRCR, et al. This is an open-access article distributed under the terms of the Creative Commons Attribution License, which permits unrestricted use, distribution, and reproduction in any medium, provided the original author and source are credited. 
Citation: Narayan Karunanithy FRCR, Raphael Uwechue MRCS, Francis Calder FRCS, NizamMamode FRCS, LetoMailli MD, et al. (2014) Endovascular Repair of Late Onset Anastomosis Site Pseudoaneurysms Complicating Renal Transplantation. J Vasc Med Surg 2: 156. doi: 10.4172/2329-6925.1000156

Page 2 of 5

\begin{tabular}{|c|c|c|c|c|c|c|}
\hline Case Number & 1 Left & 1 Right & 2 & 3 & 4 & 5 \\
\hline Age (years) & 54 & 57 & 46 & 42 & 44 & 6 \\
\hline Sex & Male & Male & Male & Female & Male & Female \\
\hline Cause of ESRF & Goodpasture's & Goodpasture's & $\begin{array}{l}\text { Focal Segmental } \\
\text { Sclerosis }\end{array}$ & $\begin{array}{c}\text { Congenital Dysplastic } \\
\text { Kidneys }\end{array}$ & $\begin{array}{c}\lg \mathrm{A} \\
\text { nephropathy }\end{array}$ & $\begin{array}{l}\text { Congenital nephrotic } \\
\text { syndrome }\end{array}$ \\
\hline Anticoagulation & Yes & Yes & Yes & Yes & No & No \\
\hline Duration after transplantation & 7 years & 10 years & 6 years & 17 years & 17 years & 1 year 8 months \\
\hline Allograft explanted & Yes & Yes & No (non-functioning) & Yes & Yes & Yes \\
\hline Presentation & $\begin{array}{l}\text { Incidental finding on } \\
\text { clinical examination }\end{array}$ & $\begin{array}{c}\text { Rupture, } \\
\text { hypovolemic shock }\end{array}$ & $\begin{array}{l}\text { Right iliac fossa pain and } \\
\text { numbness in thigh }\end{array}$ & $\begin{array}{l}\text { Incidental on CTA for } \\
\text { transplant workup }\end{array}$ & $\begin{array}{c}\text { Left iliac fossa } \\
\text { pain }\end{array}$ & $\begin{array}{l}\text { Incidental on CTA for } \\
\text { transplant workup }\end{array}$ \\
\hline Site of lesion & Left EIA & Right EIA & Right EIA & Left EIA & Left EIA & Distal aorta \\
\hline Size of lesion & $4.2 \mathrm{~cm}$ & $4.4 \mathrm{~cm}$ & $9 \mathrm{~cm}$ & $3.2 \mathrm{~cm}$ & $5.4 \mathrm{~cm}$ & $3.1 \mathrm{~cm}$ \\
\hline
\end{tabular}

$\mathrm{EIA}=$ External Iliac Artery

Table 1: Table showing patient demographics and pseudoaneurysm characteristics.

\begin{tabular}{|c|c|c|c|c|c|c|}
\hline & \multicolumn{6}{|c|}{ Case Number } \\
\hline & $1 \mathrm{Left}$ & 1 Right & 2 & 3 & 4 & 5 \\
\hline Site of lesion & Left EIA & Right EIA & Right EIA & Left EIA & Left EIA & Distal aorta \\
\hline $\begin{array}{l}\text { Endovascular } \\
\text { Repair } \\
\text { Technique }\end{array}$ & $\begin{array}{l}\text { Balloon expanded PTFE } \\
\text { covered metal stent }\end{array}$ & $\begin{array}{c}\text { Balloon expanded } \\
\text { PTFE covered } \\
\text { metal stent }\end{array}$ & $\begin{array}{c}\text { Balloon expanded } \\
\text { PTFE covered } \\
\text { metal stent }\end{array}$ & $\begin{array}{l}\text { Balloon expanded PTFE } \\
\text { covered metal stent }\end{array}$ & $\begin{array}{l}\text { Balloon expanded PTFE } \\
\text { covered metal stent }\end{array}$ & $\begin{array}{l}\text { Balloon expanded bare } \\
\text { metal stent assisted coil } \\
\text { embolisation }\end{array}$ \\
\hline $\begin{array}{c}\text { Dimension of } \\
\text { endovascular } \\
\text { device }\end{array}$ & $9 \mathrm{~mm} \times 80 \mathrm{~mm}$ stent & $\begin{array}{c}9 \mathrm{~mm} \times 56 \mathrm{~mm} \\
\text { stent }\end{array}$ & $\begin{array}{c}10 \mathrm{~mm} \times 59 \mathrm{~mm} \\
\text { stent }\end{array}$ & $9 \mathrm{~mm} \times 38 \mathrm{~mm}$ stent & $10 \mathrm{~mm} \times 59 \mathrm{~mm}$ stent & $\begin{array}{c}10 \mathrm{~mm} \times 29 \mathrm{~mm} \text { bare } \\
\text { metal stent and multiple } \\
\text { coils }\end{array}$ \\
\hline $\begin{array}{c}\begin{array}{c}\text { No. of treatment } \\
\text { sessions }\end{array} \\
\end{array}$ & 1 & 1 & 1 & 1 & 1 & 3 \\
\hline $\begin{array}{c}\text { Clinical follow } \\
\text { up }\end{array}$ & 4 years & 1 year & 1 year & 1 year & 1 year & 2 years \\
\hline$\underset{\text { up }}{\text { Imaging follow }}$ & $\begin{array}{l}\text { Duplex } 6 \text { weeks - complete } \\
\text { exclusion, patent native } \\
\text { artery } \\
\text { CTA } 3 \text { years - complete } \\
\text { exclusion, patent native } \\
\text { artery }\end{array}$ & $\begin{array}{c}\text { Duplex } 6 \\
\text { months - complete } \\
\text { exclusion, patent } \\
\text { native artery }\end{array}$ & $\begin{array}{c}\text { Duplex } \\
1 \text { year - complete } \\
\text { exclusion, patent } \\
\text { native artery }\end{array}$ & $\begin{array}{c}\text { Duplex } 6 \text { months - complete } \\
\text { exclusion, patent native } \\
\text { artery } \\
\text { CTA } 9 \text { months - complete } \\
\text { exclusion, patent native } \\
\text { artery }\end{array}$ & $\begin{array}{l}\text { CTA } 3 \text { months - complete } \\
\text { exclusion, patent native } \\
\text { artery } \\
\text { Duplex } 9 \text { months - } \\
\text { complete exclusion, patent } \\
\text { native artery }\end{array}$ & $\begin{array}{l}\text { CTA } 18 \text { months after final } \\
\text { treatment - complete } \\
\text { exclusion, patent native } \\
\text { artery }\end{array}$ \\
\hline
\end{tabular}

Table 2: Details of the endovascular repair procedure.

where the majority of adult patients have allografts anastomosed to the external iliac artery. The sizes of the pseudoaneurysms were relatively large at presentation (range $3.1 \mathrm{~cm}-9 \mathrm{~cm}$ ).

The technical details of the endovascular repair procedure, including device choice and dimensions as well as clinical and imaging follow up are presented in Table 2. All cases of pseudoaneurysms arising from the external iliac artery were treated by placement of covered stents. The distal aortic pseudoaneurysm was treated by stent assisted coil embolization and required three treatment sessions. The clinical follow up ranged from 1-4 years. The imaging follow up was heterogeneous as there is no agreed protocol. The imaging follow up ranged from 6 months -3 years. In all cases, successful exclusion of the pseudoaneurysm was confirmed on imaging.

\section{Discussion}

$5-10 \%$ of post-transplantation complications are due to a vascular cause $[8,9]$. These include acute arterial/venous thrombosis, arteriovenous fistula, renal artery stenosis, intra and extra-renal pseudoaneurysms. Extra-renal anastomosis site pseudoaneurysms are rare with a reported incidence of $<1 \%[8,9]$. The natural history of such pseudoaneurysms is not well understood but the aetiology is believed to be multifactorial. Possible causes include disruption of the anastomosis due to technical reasons [10], perivascular infection [11], immune mediated rejection [1], tissue degeneration and bleeding diathesis (e.g. warfarin). In all the cases described here, the pseudoaneurysms developed some time after surgery and are unlikely to be due to technical reasons. Even though all patients were systemically well when they presented, low grade infection leading to tissue degeneration and anastomosis breakdown cannot be excluded. Ongoing rejection may also have contributed in all cases. Increased bleeding tendency due to warfarin, taken by the first three patients, may have contributed to leakage of blood through degenerated and therefore weaker scar tissue and the formation of the pseudoaneurysms. Finally, cardiovascular factors, like high heart rate and hypertension, may have an additional contribution to vessel wall stress, tissue disruption and risk of bleeding $[12,13]$.

The mode of presentation can vary greatly between cases, as demonstrated by our case series. It may be discovered incidentally at imaging for other indications or procedures as in cases $1,3 \& 5$ (Figure 1). Localised symptoms occur when adjacent structures are compressed as in cases $2 \& 4$. Structures that may be compressed include the External Iliac Vein (leg swelling and DVT), branches of the lumbar plexus (pain, numbness and paraesthesia) and bladder (pain and frequency of micturition) [2]. Non-specific systemic features of an inflammatory response such as fever and malaise are also well recognised presentations $[3,4]$.

The role of imaging is to confirm the diagnosis and crucially determine appropriate therapy. Diagnostic modalities include Duplex Ultrasound (US), Doppler US, CTA and Magnetic Resonance Angiography (MRA). Intra-Arterial Digital Subtraction Angiography (IADSA) is now only performed at the time of Endovascular Repair. In the paediatric population and slim adults Duplex US provides adequate assessment of the native arteries and allograft anastomosis sites $[14,15]$. Doppler US may be useful in the detection and monitoring of 
Citation: Narayan Karunanithy FRCR, Raphael Uwechue MRCS, Francis Calder FRCS, NizamMamode FRCS, LetoMailli MD, et al. (2014) Endovascular Repair of Late Onset Anastomosis Site Pseudoaneurysms Complicating Renal Transplantation. J Vasc Med Surg 2: 156. doi: 10.4172/2329-6925.1000156

Page 3 of 5

(a)

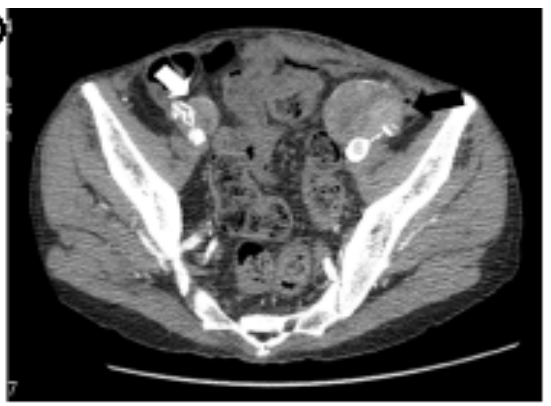

(t)

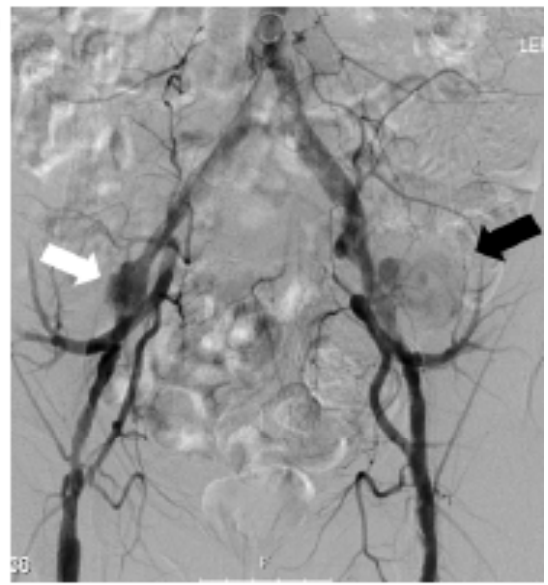

(c)

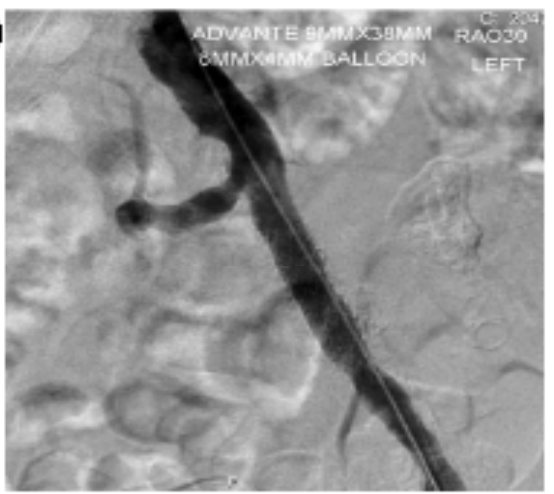

Figure 1: (a). (Case 1) Pre-procedure carotid duplex demonstrating To \& Fro waveform of the right ICA." is wrong. Please delete and add "Figure 1: (a) (Case 1) Axial section of the CT angiogram in Case 1 showing the left external iliac artery pseudoaneurysm (black arrow) and a smaller right external iliac artery pseudoaneurysm (white arrow)."

anastomosis site pseuodoaneurysms. However the pseudoaneurysm may lie deep within the pelvis and patient factors like body habits and overlying bowel gas may limit its routine use. CTA is by far the most commonly performed imaging modality for this indication. Whilst MRA benefits from not involving ionising radiation, it is not in routine clinical use as first line investigation currently. The important factors to take into account when considering treatment of the pseudoaneurysm are its overall size, the size of the neck and the relationship of the pseudoaneurysm to branch arteries.

The management strategy of very small pseudoaneurysms $(<10 \mathrm{~mm})$ is most often conservative, although there is currently insufficient literature on their natural progression. Reports indicate that pseudoaneurysms can develop many years after transplantation
[16-18]. As case 2 illustrated, rapid growth can occur over a short time period, in this case to $9 \mathrm{~cm}$ in 12 months. Furthermore, the size at which pseudoaneurysms rupture is also unpredictable (Figure 2). Hence if pseudoaneurysms are detected and conservative therapy followed, close follow up with serial US or CTA is prudent.

Larger pseudoaneurysms do require emergent treatment to minimise the risk of rupture (Figure 3). Endovascular repair is most often achieved by excluding flow into the pseudoaneurysm by percutaneous placement of a covered stent graft within the native artery as described in cases 1-4 $[1,19]$. Even in the emergency setting of pseudoaneurysm rupture successful endovascular management with stent grafts has been reported [16]. When compared to open surgical repair, endovascular repair is associated with reduced morbidity and shorter length of stay [1]. Very good patency rates of $100 \%, 98 \%, 95 \%$ and $88 \%$ have been reported at $1,2,3$ and 4 years respectively in the literature for iliac artery aneurysms treated with stent grafts [20].

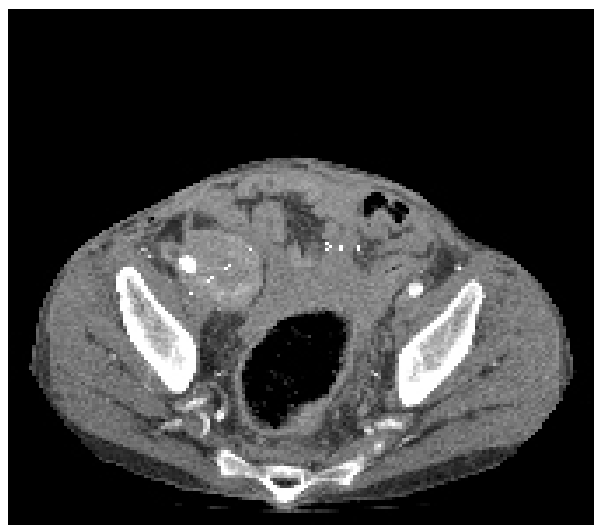

Figure 2: 3 years after the initial presentation, Case 1 presented with rupture of the right (contralateral) anastomosis site pseudoaneurysm that measured $4.8 \mathrm{~cm}$ in diameter. Again successful endovascular treatment was carried out.
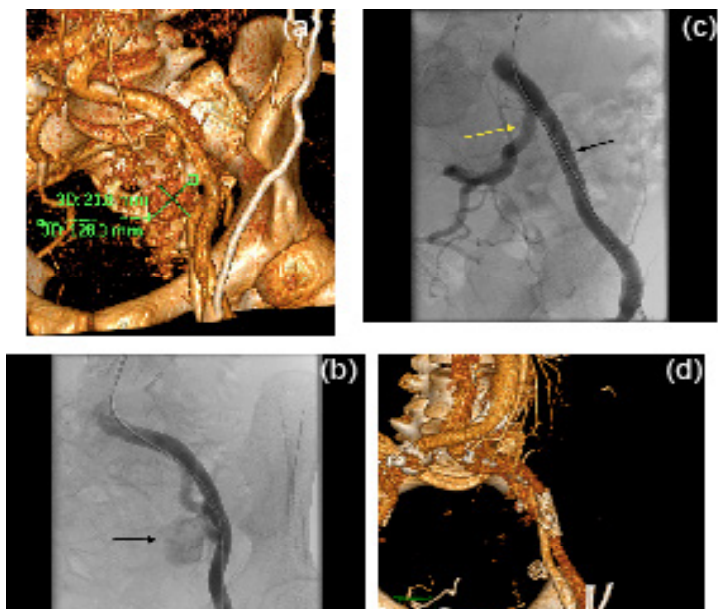

Figure 3: (a). Volume rendered CT image demonstrates the pseudoaneurysm arising from the left external iliac artery in Case 3 and its dimensions. (b). IADSA images from Case 3 demonstrating the large pseudoaneurysm arising from the left External Iliac Artery (black arrow).

(c). Post endovascular repair with a stent graft (black arrow). Note preserved left Internal Iliac Artery (yellow arrow).

(d). Follow up CT at 8 months shows patent stent graft and exclusion of the pseudoaneurysm. 
Citation: Narayan Karunanithy FRCR, Raphael Uwechue MRCS, Francis Calder FRCS, NizamMamode FRCS, LetoMailli MD, et al. (2014) Endovascular Repair of Late Onset Anastomosis Site Pseudoaneurysms Complicating Renal Transplantation. J Vasc Med Surg 2: 156. doi: 10.4172/2329-6925.1000156

Page 4 of 5
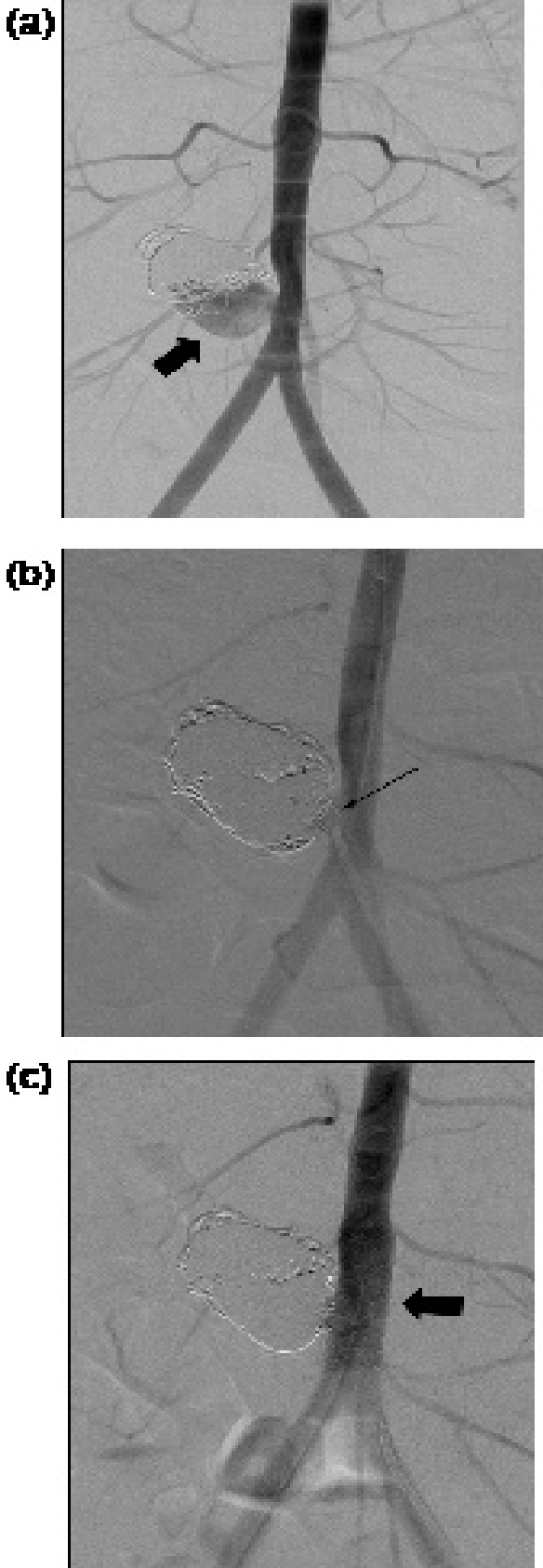

Figure 1: (a). (a) IADSA image for Case 5 performed when she was aged 17 and had had two previous coil embolisation procedures to treat her anastomosis site pseudoaneurysm arising from the aorta; pre-treatment IADSA demonstrates persistent flow into the pseudoaneurysm sac (solid arrow).

(b). Peri-procedure image showing partial prolapse of a coil into the aorta

(c). (c) IADSA after completion of stent assisted coil embolisation demonstrating complete exclusion of the pseudoaneurysm sac.

Transplant allografts are commonly anastomosed to the External Iliac Artery (Cases 1-4). In this vascular territory the relationship of the pseudoaneurysm to the Internal Iliac Artery (IIA) is an important consideration. Attempts should be made where possible to preserve this artery. Conversely if the pseudoaneurysm origin is in very close proximity to the IIA origin, endovascular repair with covered stents is likely to compromise inflow to the IIA. In this scenario, backfilling of the IIA will almost certainly occur which in turn may lead to continued perfusion of the pseudoaneurysm sac. Hence endovascular repair should include closing the 'backdoor' (IIA) by coil embolization prior to closing the 'front door' (Common Iliac Artery) by placement of a stent graft.

Occasionally the location of the pseudoaneurysm may make it unsuitable for endovascular stent graft placement as illustrated in Case 5 (Figure 4). The location of the pseudoaneurysm here was at the aortic bifurcation in a 4 year old whose aorta was likely to expand in size. This case was managed effectively by stent-assisted placement of coils to fill and cause thrombosis of the pseudoaneurysm sac. This form of endovascular repair has been effectively utilised to treat saccularpseudoaneurysms at other anatomical locations including the intra-cranial and visceral arteries $[21,22]$.

The presence or suspicion of sepsis with pseudoaneurysm formation makes the management somewhat more complicated. The significant benefit of open surgery in these circumstances is that debridement and washout can be performed before definitive aneurysm repair $[5,6]$. Although endovascular repair using prosthetic stent grafts have been described in the literature for treatment of pseudoaneurysms associated with infection it should be avoided where possible [19]. It is the authors' practise to utilise endovascular repair in infective pseudoaneurysms when either open repair is contraindicated or in emergency situations to gain temporary control of haemorrhage allowing a definitive open surgical procedure to be planned.

A further consideration when contemplating endovascular repair is the possibility that patients may require antiplatelet or anticoagulation therapy. There is currently insufficient data on the benefit of either such therapy to support their use following stent graft implantation. However, it is routine practice after peripheral arterial intervention to place the patient on single agent antiplatelet therapy and this may appear to be a sensible strategy for this patient group [23]. As the stent is likely to become endothelialised within 3 months, i.e. incorporated into the arterial wall, there is no logical reason to keep the patient on prolonged antiplatelet therapy. As arterial thrombosis is thought to be the result of platelet aggregation rather than thrombin mediated, there does not appear to be a need to recommend anticoagulation therapy following stent graft implantation [23]. If the primary means of treating the pseudoaneurysm is by coil embolization, it is the author's view that no antiplatelet therapy is required as metal work is not in direct contact with flowing blood. In patients already on warfarin, there is no need to consider additional antiplatelet treatment.

Ultrasound-guided percutaneous thrombin injection into the pseudoaneurysm sac has been reported as sole therapy or combined with endovascular repair [7]. This technique should only be contemplated when the neck of the pseudoaneurysm is relatively narrow $(<5 \mathrm{~mm})$ as larger neck widths carry significant risk of thrombin escaping from the pseudoaneurysm and causing catastrophic distal embolization [24]. Further repeat procedures may be required to treat the pseudoaneurysm adequately $[25,26]$.

\section{Conclusion}

Our experience has shown that extra-renal pseudoaneurysms although rare are a potentially life threatening complication following renal transplantation or transplant nephrectomy. They can present in a variety of ways and a long time after surgery. Endovascular repair is safe and effective for treatment of this condition and results in durable short and mid-term outcome. Clinicians should be vigilant and imaging performed if suspected especially in patients on anticoagulation. 
Citation: Narayan Karunanithy FRCR, Raphael Uwechue MRCS, Francis Calder FRCS, NizamMamode FRCS, LetoMailli MD, et al. (2014) Endovascular Repair of Late Onset Anastomosis Site Pseudoaneurysms Complicating Renal Transplantation. J Vasc Med Surg 2: 156. doi: 10.4172/2329-6925.1000156

Page 5 of 5

\section{Acknowledgement}

Part of this work was presented as a poster at the British Transplantation Society 2013 meeting in Plymouth, UK. In addition, it was presented as a mini ora presentation at the European Society for Organ Transplantation in Vienna, Austria, in September 2013.

\section{References}

1. Bracale UM, Carbone F, del Guercio L, Viola D, D'Armiento FP, et al. (2009) External iliac artery pseudoaneurysm complicating renal transplantation. Interact Cardiovasc Thorac Surg 8: 654-660.

2. Luzzio CC, Waclawik AJ, Gallagher CL, Knechtle SJ (1999) Iliac artery pseudoaneurysm following renal transplantation presenting as lumbosacra plexopathy. Transplantation 67: 1077-1078.

3. Peel RK, Patel J, Woodrow G (2003) Iliac artery false aneurysm following renal allograft: presentation with non-specific inflammatory response and treatment by endovascular stent graft. Nephrol Dial Transplant 18: 1939-1940.

4. Levi J, Zevin D, Barak I, Agmon M (1979) Prolonged fever and anemia as the sole manifestations of a false aneurysm in a transplant patient. Isr J Med Sci 15: $910-912$

5. Garrido J, Lerma JL, Heras M, Labrador PJ, García P, et al. (2003) Pseudoaneurysm of the iliac artery secondary to Aspergillus infection in two recipients of kidney transplants from the same donor. Am J Kidney Dis 41 : 488-492.

6. Saidi RF, Fasola C, El-Ghoroury M, Oh H (2004) Arterial anastomosis disrupton in two kidney recipients of contaminated grafts from a donor with Gorham's syndrome. Transplant Proc 36: 1392-1394.

7. Reus M, Morales D, Vazquez V, Llorente S, Alonso J (2002) Ultrasound-guided percutaneous thrombin injection for treatment of extrarenal pseudoaneurysm after renal transplantation. Transplantation 74:882-884

8. Goldman MH, Tilney NL, Vineyard GC, Laks H, Kahan MG, et al. (1975) A twenty year survey of arterial complications of renal transplantation. Surg Gynecol Obstet 141: 758-760.

9. Palleschi J, Novick AC, Braun WE, Magnusson MO (1980) Vascular complications of renal transplantation. Urology 16: 61-67.

10. Guleria S, Ahmad N, Pollard SG, Newstead CG, Lodge JP (1998) Transplant renal artery aneurysm following venous patch repair of a traction injury to the renal artery. Nephrol Dial Transplant 13: 1577-1578.

11. Lee CH, Kao YC, Chan WP (2011) Pseudoaneurysm with candidal infection after renal transplantation. Intern Med 50: 2679-2680.

12. Scicchitano $P$, Carbonara S, Ricci G, Mandurino $C$, Locorotondo $M$, et al (2012) HCN channels and heart rate. Molecules 17: 4225-4235.

13. Heidland UE, Strauer BE (2001) Left ventricular muscle mass and elevated heart rate are associated with coronary plaque disruption. Circulation 104 $1477-1482$.
14. Mutze S, Türk I, Schönberger B, Filimonow SI, Bollow M, et al. (1997) Colour-coded duplex sonography in the diagnostic assessment of vascular complications after kidney transplantation in children. Pediatr Radiol 27: 898902

15. Koo CK, Rodger S, Baxter GM (1999) Extra-renal pseudoaneurysm: an uncommon complication following renal transplantation. Clin Radiol 54: 755758.

16. Diller R, Hölzen J, Senninger N, Kramer S (2006) Interventional stenting for ruptured iliac aneurysm following transplant nephrectomy. Transplant Proc 38 : 718-720.

17. Moosavi CA, Gujrathi SK, Friedman A, Fox D, Silberzweig JE (2008) Endovascular repair of symptomatic renal transplant site pseudoaneurysm. Vasc Endovascular Surg 42: 607-609.

18. Phillips AO, Patel NR, Snowden SA, Bewick M, Hendry BM (1993) lliac artery aneurysm following renal transplantation. Nephrol Dial Transplant 8: 456-457.

19. Zavos G, Pappas P, Kakisis JD, Leonardou P, Manoli E, et al. (2005) Endovascular repair as first-choice treatment of iliac pseudoaneurysms following renal transplantation. Transplant Proc 37: 4300-4302.

20. Scheinert D, Schröder M, Steinkamp H, Ludwig J, Biamino G (2000) Treatment of iliac artery aneurysms by percutaneous implantation of stent grafts. Circulation 102: III253-258.

21. lijima A, Piotin M, Mounayer C, Spelle L, Weill A, et al. (2005) Endovascula treatment with coils of 149 middle cerebral artery berry aneurysms. Radiology 237: 611-619.

22. Chadha M, Ahuja C (2009) Visceral artery aneurysms: diagnosis and percutaneous management. Semin Intervent Radiol 26: 196-206.

23. Alonso-Coello P, Bellmunt S, McGorrian C, Anand SS, Guzman R, et al. (2012) Antithrombotic therapy in peripheral artery disease: Antithrombotic Therapy and Prevention of Thrombosis, 9th ed: American College of Chest Physicians Evidence-Based Clinical Practice Guidelines. Chest 141: e669S-90S.

24. Ahmad F, Turner SA, Torrie P, Gibson M (2008) latrogenic femoral artery pseudoaneurysms--a review of current methods of diagnosis and treatment Clin Radiol 63: 1310-1316.

25. Sharron JA, Esterl RM, Washburn WK, Abrahamian GA (2009) Surgical treatment of an extrarenal pseudoaneurysm after kidney transplantation. Vasc Endovascular Surg 43: 317-321.

26. Nicholson AA, Patel J, McPherson S, Shaw DR, Kessel D (2006) Endovascula treatment of visceral aneurysms associated with pancreatitis and a suggested classification with therapeutic implications. J Vasc Interv Radiol 17: 1279-1285. 